\title{
The Influence of Trace Elements on the Nature of the Nuclei of the Graphite in Ductile Iron
}

\author{
Gorka Alonso ${ }^{1, a^{*}}$, Doru M. Stefanescu ${ }^{2, b}$, Esther De la Fuente ${ }^{3, c}$, \\ Pello Larrañaga ${ }^{1, \mathrm{~d}}$ and Ramon Suarez ${ }^{1,3, \mathrm{e}}$ \\ ${ }^{1}$ Ik4-Azterlan, Durango (Bizkaia), Spain \\ ${ }^{2}$ Ohio State Univ., Columbus, Ohio and Univ. of Alabama, Tuscaloosa, Alabama, USA \\ ${ }^{3}$ Veigalan Estudio 2010 S.L.U., Durango (Bizkaia), Spain \\ agalonso@azterlan.es, bstefanescu.1@osu.edu, cedelafuente@azterlan.es, \\ dplarranaga@azterlan.es, ${ }^{\mathrm{e}}$ rsuarez@azterlan.es
}

Keywords: ductile iron, nucleation, inoculant, nuclei

\begin{abstract}
Nucleation mechanisms and the effect of minor elements added with the inoculants are still a subject of extensive research in ductile iron. Oxides, sulfides, silicates and nitrides have been reported to be nuclei for graphite precipitation. Those compounds originate both from the nodulizing treatment and the inoculation process.

Previous research works have shown that titanium nitrides or carbonitrides play an active role in graphite nucleation. In order to determine the efficiency and nature of nitrides that can act as nuclei for graphite, and the possible effect of the trace elements added with the inoculant, melts with titanium contents ranging from $0.007 \%$ to $0.036 \%$ were produced and poured into standard thermal analysis cups, with and without inoculation. Different inoculants rich in titanium, cerium, aluminum or zirconium were used. Two cups were produced with each inoculant, one cooled down to room temperature, and the other quenched in brine immediately after pouring. Nucleation sites were characterized through detector, spectrum, mapping and line scans of a FEG-SEM equipment.

Most of the analyzed nuclei exhibited two or three different inclusions: magnesium sulfides or $\mathrm{Mg}-\mathrm{Ca}$ oxy-sulfides, Mg or Al oxides, and Ti carbo-nitrides or Mg-Si-Al nitrides. The appearance of each type of nitrides is directly related to the titanium content in the base melt. When titanium was added in the inoculant, no titanium nitrides were noticeable. The zirconium added with the inoculant promoted more complex nitrides that appeared in higher amount. Cerium appears occasionally forming sulfides. Aluminum stimulates the formation of complex nitrides. No differences in the nature of the nuclei were observed between the samples quenched and the ones obtained at room temperature, which assures the methodology approach.
\end{abstract}

\section{Introduction}

The metallurgical characteristics and final mechanical properties of a casting are directly related to the shape, size and distribution of the graphite present in the matrix [1,2]. This is why the study of graphite formation is one of the key steps in understanding the solidification process of cast iron [3-7]. The formation of this graphite is directly related to the inoculation processes used in cast irons [8-9], through which the nucleation capacity of the metal is enhanced with the addition of a series of specific compounds (usually oxides, sulfides and silicates) [4,8], which generate the compounds that are selected by the atoms of carbon as nucleation sites for graphite.

Foundries are often confused by the extensive range of inoculants and modularizing agents that are available from the ferroalloy producers. Pure silicon and pure ferrosilicon alloys are not very efficient as ladle inoculants. Most inoculants are based on ferrosilicon containing about 50-75\% silicon, or on ferrosilicon-graphite mixtures and contain up to around 5\% of carefully controlled levels of elements such as $\mathrm{Ca}, \mathrm{Al}, \mathrm{Zr}, \mathrm{Ba}, \mathrm{Sr}, \mathrm{La}, \mathrm{Ce}$ and $\mathrm{Ti}$, that are capable of combining with sulfur and oxygen in the iron to form micro-inclusions having a suitable surface and crystallographic characteristics to heterogeneously nucleate graphite. 
The nucleation potential of an inoculant is determined by the presence of these minor elements [8-10] as well as by the melt temperature, the method of addition and the holding time. A large number of studies corroborate the effectiveness of calcium as element that promotes the nuclei of graphite [11, 12]. Calcium is used as the primary reactive element in inoculation and it is fundamental for eutectic graphite nucleation [13]. Barium functions similar to calcium (strong deoxidizer), and contributes to a strong nucleation effect, although it seems to give a better efficiency to the inoculants over a wider temperature range than calcium alone (above $1480^{\circ} \mathrm{C}$ ) [14]. Zirconium is a deoxidizing element with the ability to react with nitrogen forming Zr-nitrides which may act as nuclei for graphite during the solidification [15]. Aluminum is known as a good stabilizer of graphite and as a good neutralizer of nitrogen too, with which can combine to form complex Mg-Al-Si nitrides [16]. Titanium has a very high affinity to $\mathrm{O}$ and $\mathrm{S}$ although in previous studies by these researchers it seemed to combine better with the nitrogen and carbon to form $\operatorname{Ti}(\mathrm{CN})[17,18]$. Cerium has a strong affinity to sulfur and oxygen, resulting in the formation of highly stable cerium oxides, sulfide and oxy-sulfides [19, 20].

The present investigation was conducted to analyze the influence of these trace elements in the different type of nonmetallic inclusions (sulfides, carbides, oxides, nitrides and silicates) which can appear both in the iron matrix and in the nuclei of the graphite spheroids. The nature of these inclusions was studied through the use of advanced Field Emission Gun Scanning Electron Microscope (FEG-SEM) techniques, such as spectrums, mappings and line scan, and the use of different detectors. The study was carried on slightly hypereutectic irons, inoculated and noninoculated, and with different levels of titanium in the melt.

\section{Experimental Strategy}

\section{Melting and Casting}

Six heats with different titanium contents $(0.007,0.011,0.014,0.02,0.03$ and 0.036$)$ were produced in a $100 \mathrm{~kg}$ medium frequency induction furnace $(250 \mathrm{~Hz}, 100 \mathrm{Kw})$. The charge for each heat consisted of $28 \mathrm{~kg}$ of ductile iron returns (with various Ti contents) and $22 \mathrm{~kg}$ of high purity iron. Predetermined amounts of a commercial graphite $(98.9 \% \mathrm{C}, 0.03 \% \mathrm{~S})$ and of FeSi alloy $(74,6 \% \mathrm{Si}, 0.3 \% \mathrm{Ca}, 0.7 \% \mathrm{Al})$ were also added to the metallic charges. After melting, the composition was checked and adjusted according to the required target. After superheating to $1500^{\circ} \mathrm{C}$, the iron was transferred into the pouring ladle for $\mathrm{Mg}$ treatment with $0.55 \mathrm{~kg}(1.1 \mathrm{wt} . \%$ of the batch weight) of a FeSiMg alloy $(47.2 \% \mathrm{Si}, 6.02 \% \mathrm{Mg}, 1.15 \% \mathrm{Ca}, 0.24 \% \mathrm{Al}, 0.3 \% \mathrm{Mn}$ and $0.88 \% \mathrm{RE}$ ) by the sandwich method. The FeSiMg alloy was positioned at the bottom of the ladle and then covered with steel scrap, before tapping the melt from the furnace. The chemical compositions of the experimental heats are presented in Table 1. In addition to the elements listed in the table, the alloys contained $0.04 \% \mathrm{Cr}, 0.02 \% \mathrm{Ni}, 0.01 \% \mathrm{Mo}, 0.07 \% \mathrm{Cu}$ and less than $0.01 \% \mathrm{Al}$.

Table 1. Chemical composition (mass\%) of experimental cast irons

\begin{tabular}{ccccccccc}
\hline Heat & $\mathbf{C}$ & $\mathbf{S i}$ & $\mathbf{M n}$ & $\mathbf{P}$ & $\mathbf{S}$ & $\mathbf{M g}$ & $\mathbf{T i}$ & $\mathbf{N}$ \\
\hline 1 & 3,69 & 2,01 & 0,17 & 0,016 & 0,007 & 0,053 & 0,007 & 0,0041 \\
2 & 3.75 & 1.91 & 0.18 & 0.021 & 0.006 & 0.056 & 0.011 & NA \\
3 & 3.68 & 1.87 & 0.24 & 0.005 & 0.009 & 0.044 & 0.014 & 0.0044 \\
4 & 3.30 & 2,00 & 0.19 & 0.018 & 0.01 & 0.041 & 0.02 & NA \\
5 & 3.78 & 1.93 & 0.22 & 0.016 & 0.009 & 0.038 & 0.03 & 0.0043 \\
6 & 3.55 & 1.84 & 0.21 & 0.023 & 0.009 & 0.053 & 0.036 & 0.0043 \\
\hline
\end{tabular}

NA: not analyzed

A total of 26 standard thermal analysis (TA) cups were poured from the melts (sixteen inoculated and ten not inoculated). Inoculation was made directly in the cups through the addition of $0.2 \%$ of different commercial inoculants whose compositions are summarized in Table 2 . The 
liquid treatment of the various TA cups and the amount of Ti in the base iron are shown in Table 3 . The solidification of the iron was interrupted by quenching in brine for thirteen of these TA cups, to prevent excessive growth of spheroidal graphite. After cooling to room temperature, the cups were sectioned and prepared for metallographic examination. To confirm that quenching did not change the nature of the nuclei, but only the size of the analyzed graphite, several heats were examined both after quenching, and after solidification without quenching.

Table 2. Chemical composition (mass\%) of the inoculants

\begin{tabular}{cccccccccccc}
\hline Symbol & $\mathbf{S i}$ & $\mathbf{A l}$ & $\mathbf{C a}$ & $\mathbf{M n}$ & $\mathbf{T i}$ & $\mathbf{Z r}$ & $\mathrm{Ce}$ & $\mathbf{B a}$ & $\mathbf{M g}$ & $\mathbf{B i}$ & $<\mathbf{0 , 1 \%}$ \\
\hline $\mathrm{Al}$ & 72.9 & $\mathbf{3 . 8 1}$ & 1.42 & 0.18 & 0.07 & $<0.05$ & $<0.05$ & 0.38 & $<0.10$ & $<0.02$ & $\mathrm{Sr}, \mathrm{Ce}, \mathrm{La}$ \\
$\mathrm{Ti}$ & 52.9 & 1.16 & 0.89 & 0.32 & $\mathbf{9 . 3 7}$ & 0.06 & 0.07 & $<0.1$ & $<0.10$ & $<0.02$ & $\mathrm{Sr}, \mathrm{Ce}, \mathrm{La}$ \\
$\mathrm{BaBiCe}$ & 70.0 & 0,82 & 1,49 & 0.15 & 0.10 & $<0.05$ & $\mathbf{0 . 2 0}$ & $\mathbf{0 . 5 3}$ & $<0.10$ & $\mathbf{0 . 3 5}$ & $\mathrm{Sr}$ \\
$\mathrm{Ce}$ & 70.6 & 0.87 & 1.08 & 0.2 & 0.06 & 0.1 & $\mathbf{1 . 6 1}$ & $<0.1$ & $<0.10$ & $<0.02$ & $\mathrm{Sr}, \mathrm{Ce}, \mathrm{La}$ \\
$\mathrm{ZrMn}$ & 62.6 & 1.01 & 1.79 & $\mathbf{5 . 9 6}$ & 0.13 & $\mathbf{6 . 7 7}$ & $<0.05$ & 0.65 & 0.22 & $<0.02$ & $\mathrm{Sr}, \mathrm{Ce}, \mathrm{La}$ \\
\hline
\end{tabular}

Table 3. Liquid treatment of TA cups

\begin{tabular}{|c|c|c|c|c|c|}
\hline Heat & $\begin{array}{c}\text { \% } \mathrm{Ti} \text { in } \\
\text { melt }\end{array}$ & Sample & Inoculant & $\begin{array}{c}\text { Nodule } \\
\text { Count } \\
\left(\mathrm{mm}^{\wedge} 2\right)\end{array}$ & $\begin{array}{c}\text { No. of } \\
\text { nuclei } \\
\text { analyzed }\end{array}$ \\
\hline 1 & 0.007 & 1.1 & none & $x$ & 10 \\
\hline \multirow{2}{*}{2} & 0.011 & 2.1 & $\mathrm{Al}$ & 333 & 17 \\
\hline & 0.011 & 2.2 & $\mathrm{BaBiCe}$ & 341 & 15 \\
\hline \multirow{3}{*}{3} & \multirow{3}{*}{0.014} & 3.1 & none & 145 & 16 \\
\hline & & 3.2 & $\mathrm{Ti}$ & 275 & 11 \\
\hline & & 3.3 & $\mathrm{Ce}$ & 352 & 11 \\
\hline \multirow{2}{*}{4} & \multirow{2}{*}{0.02} & 4.1 & none & 340 & 11 \\
\hline & & 4.2 & ZrMn & 400 & 12 \\
\hline \multirow{2}{*}{5} & \multirow{2}{*}{0.03} & 5.1 & none & 430 & 13 \\
\hline & & 5.2 & ZrMn & 550 & 11 \\
\hline \multirow{3}{*}{6} & \multirow{3}{*}{0.036} & 6.1 & none & 106 & 12 \\
\hline & & 6.2 & $\mathrm{Ti}$ & 179 & 12 \\
\hline & & 6.3 & $\mathrm{Ce}$ & 169 & 11 \\
\hline
\end{tabular}

\section{Characterization}

Extensive Field Emission Gun Scanning Electron Microscope (FEG-SEM) examination of the graphite nodules was carried out on non-etched samples. To identify possible nucleation sites an Ultra PLUS Carl Zeiss SMT $(0.8 \mathrm{~mm}$ resolution at $30 \mathrm{kV})$ in the STEM mode was used in combination with an X-Max 20 Oxford Instruments EDX detector with a resolution of $127 \mathrm{eV} / \mathrm{mm}^{2}$. Three different detectors were used for the generation of images: a) in-Lens detector (annular SE detector) for the surface structure; b) Everhart-Thornley type detector (SE2) for topography; c) Angular Selective Backscattered electron detector (AsB) for compositional contrast. In addition, this investigation was complemented with spectrums, mappings and line scans, to analyze the main elements present in the inclusions and to estimate the type of compounds.

An example of this procedure is illustrated in Figure 1 showing a graphite spheroid with growing around a complex inclusion. Three different zones are identified. Spectrums 1 and 3 are similar, indicating a clear presence of $\mathrm{C}, \mathrm{N}, \mathrm{Ti}$ and $\mathrm{Zr}$. The spectrum for position 2 reveals two clear peaks of $\mathrm{Mg}$ and $\mathrm{S}$. The analysis of the X-ray composition maps presented in Figure 2 confirms the results suggested by the spectrums, with an important concentration of $\mathrm{S}, \mathrm{Mg}, \mathrm{Ca}$ and $\mathrm{O}$ in the core surrounded partially by an important concentration of $\mathrm{C}, \mathrm{Ti}, \mathrm{N}$ and $\mathrm{Zr}$. 

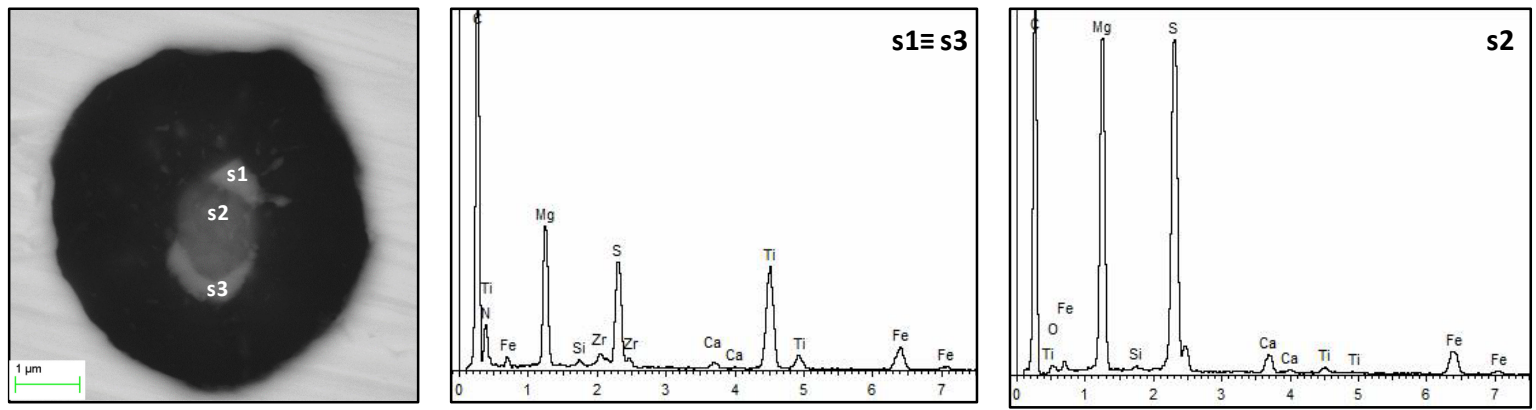

Figure 1. Graphite nodule from sample 5.2. WDX/SEM spectrums at three different positions on the inclusion
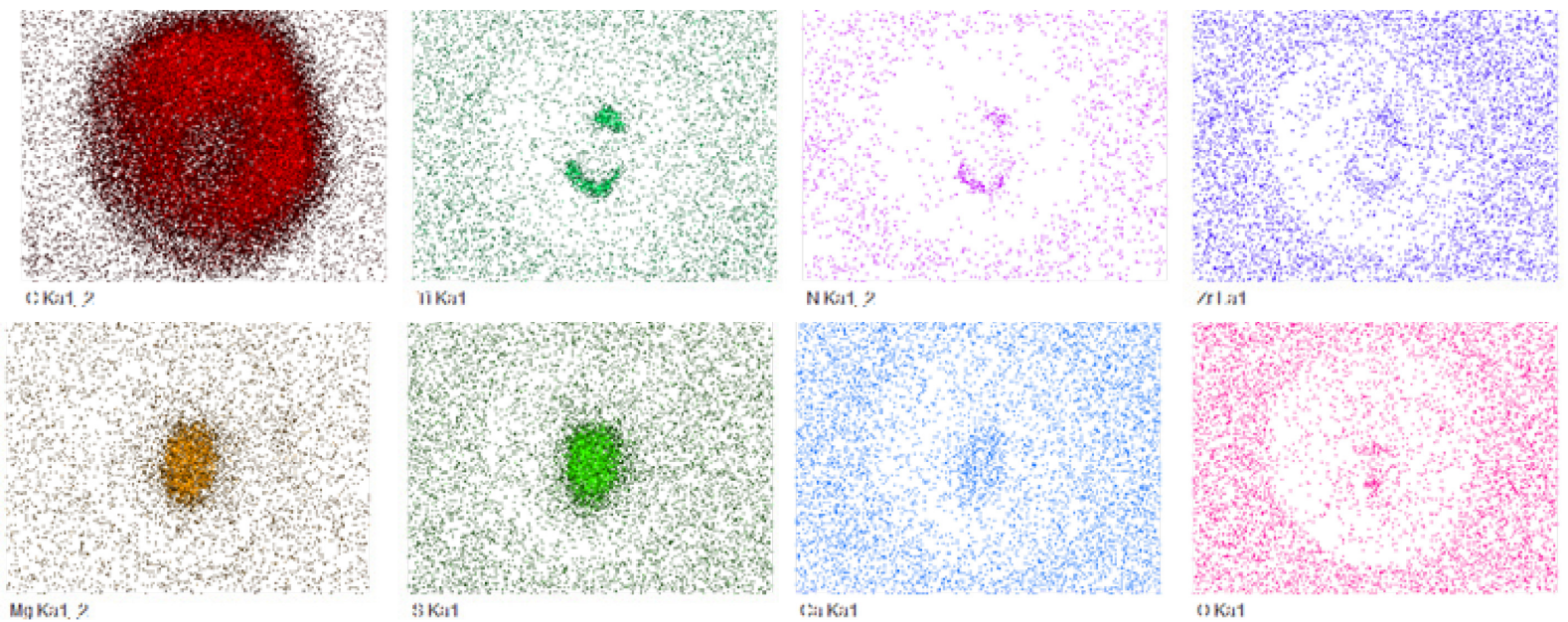

Figure 2. X ray composition maps on the graphite nodule in Figure 1

A more thorough analysis using X-ray concentration graphs reveals that $\mathrm{C}, \mathrm{Ti}, \mathrm{N}$ and $\mathrm{Zr}$ show composition peaks at the same position (Figure 3). Then, $\mathrm{Ca}, \mathrm{S}$ and $\mathrm{Mg}$ also present coincidental maxima. Finally, the $\mathrm{O}$ maximum is situated in the same position as the maximum for $\mathrm{Mg}$. Thus, this nucleus appears to be formed by a $\mathrm{Mg}$ oxide surrounded by a big rounded $\mathrm{Mg}$-Ca sulfide, whose growth in some directions was restricted by two Ti-Zr carbonitrides with a clear cubic shape.
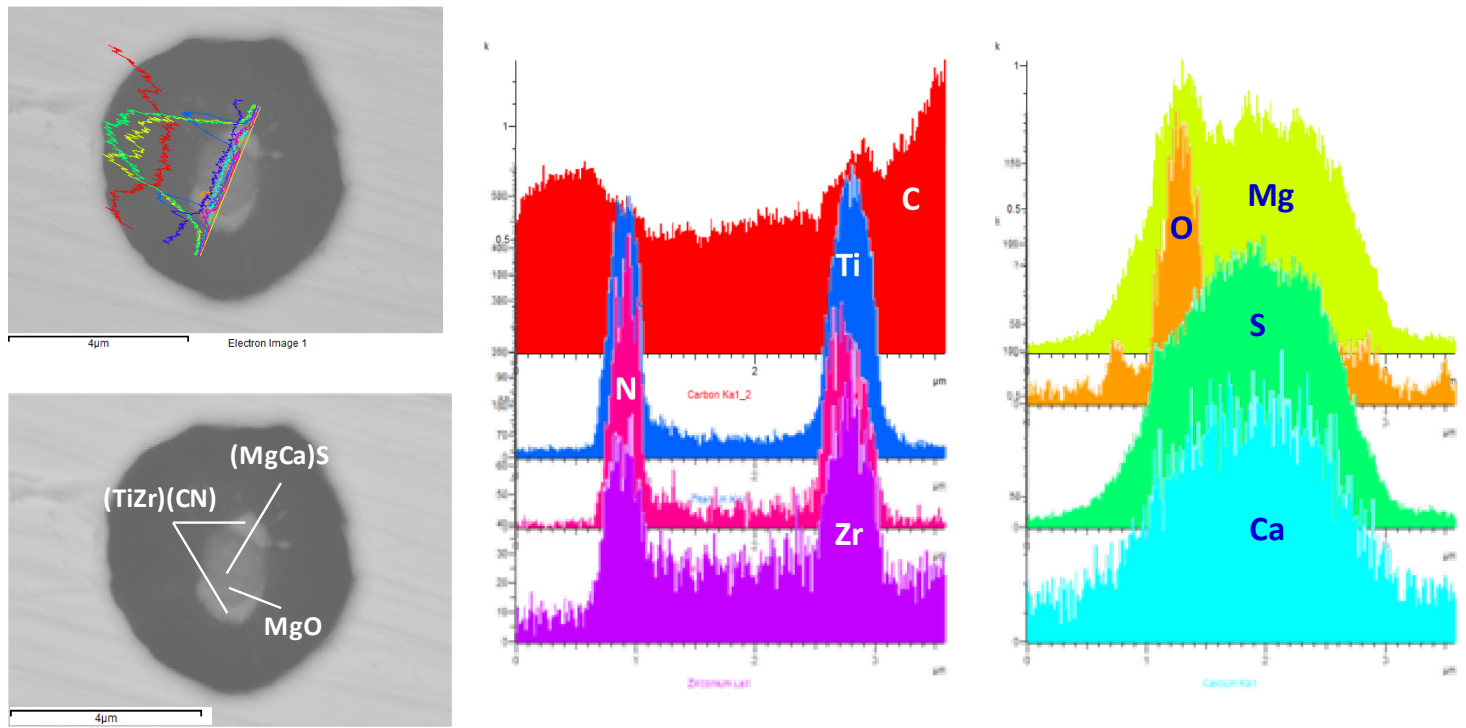

Figure 3. X ray concentration graphs in the graphite nodule in Figure 1 


\section{Experimental Results}

A summary of the different inclusions detected in the graphite nodules as a function of the inoculant and of the level of titanium in the melt is shown in Table 4. A classification between low (0.007-0.014) and high (0.020-0.036) percentages of Ti in the base iron has been carried out.

Table 4. The probability of finding a certain inclusion in the core of the graphite nodules

\begin{tabular}{|c|c|c|c|c|c|c|c|c|c|}
\hline Sample & $\begin{array}{l}\text { \% Ti in base } \\
\text { iron }\end{array}$ & Inoc. & TiCN & $\frac{(\mathrm{MgSiAl})}{\mathrm{N}}$ & $\begin{array}{l}\text { Sul- } \\
\text { fides }\end{array}$ & Oxides & $\begin{array}{c}\text { Oxy- } \\
\text { sulfides }\end{array}$ & $\begin{array}{l}\text { Phos- } \\
\text { phides }\end{array}$ & Silicates \\
\hline 1.1 & 0.007 & none & $0 \%$ & $0 \%$ & $90 \%$ & $50 \%$ & $10 \%$ & $10 \%$ & $40 \%$ \\
\hline 2.1 & \multirow{2}{*}{0.011} & $\mathrm{Al}$ & $0 \%$ & $53 \%$ & $82 \%$ & $45 \%$ & $27 \%$ & $9 \%$ & $0 \%$ \\
\hline 2.2 & & $\mathrm{BaBiCe}$ & $0 \%$ & $59 \%$ & $71 \%$ & $35 \%$ & $12 \%$ & $12 \%$ & $0 \%$ \\
\hline 3.1 & \multirow{3}{*}{0.014} & none & $0 \%$ & $25 \%$ & $19 \%$ & $38 \%$ & $81 \%$ & $0 \%$ & $0 \%$ \\
\hline 3.2 & & $\mathrm{Ti}$ & $0 \%$ & $27 \%$ & $55 \%$ & $36 \%$ & $36 \%$ & $18 \%$ & $0 \%$ \\
\hline 3.3 & & $\mathrm{Ce}$ & $0 \%$ & $64 \%$ & $64 \%$ & $36 \%$ & $9 \%$ & $0 \%$ & $0 \%$ \\
\hline 4.1 & \multirow{2}{*}{0.02} & none & $91 \%$ & $55 \%$ & $55 \%$ & $18 \%$ & $55 \%$ & $0 \%$ & $0 \%$ \\
\hline 4.2 & & ZrMn & $92 \%$ & $25 \%$ & $100 \%$ & $42 \%$ & $0 \%$ & $0 \%$ & $0 \%$ \\
\hline 5.1 & \multirow{2}{*}{0.03} & none & $85 \%$ & $46 \%$ & $8 \%$ & $31 \%$ & $85 \%$ & $0 \%$ & $0 \%$ \\
\hline 5.2 & & $\mathrm{ZrMn}$ & $91 \%$ & $27 \%$ & $27 \%$ & $55 \%$ & $73 \%$ & $0 \%$ & $0 \%$ \\
\hline 6.1 & \multirow{3}{*}{0.036} & none & $92 \%$ & $0 \%$ & $58 \%$ & $8 \%$ & $50 \%$ & $0 \%$ & $0 \%$ \\
\hline 6.2 & & $\mathrm{Ti}$ & $92 \%$ & $0 \%$ & $75 \%$ & $42 \%$ & $17 \%$ & $0 \%$ & $0 \%$ \\
\hline 6.3 & & $\mathrm{Ce}$ & $100 \%$ & $0 \%$ & $27 \%$ & $55 \%$ & $73 \%$ & $0 \%$ & $0 \%$ \\
\hline
\end{tabular}

LOW PERCENTAGE OF Ti (0.007-0.014\%)

No $(\mathrm{TiC}) \mathrm{N}$ was detected in the nuclei of graphite nodules from irons produced from low-Ti base iron. Sulfides were revealed as the predominant inclusions. Normally these are $\mathrm{Mg}$-Ca sulfides, although in some cases RE sulfides can also appear (La mainly). The sulfides can nucleate on $\mathrm{Mg}$ oxides (Figure $4 \mathrm{a})$, and usually they were accompanied by $(\mathrm{MgSiAl}) \mathrm{N}$, which seem to restrict their growth (Figure 4b). Some of the complex Mg-Si-Al nitrides appear to nucleate on AlN. They can act as direct nucleants despite their higher disregistry with graphite [14].

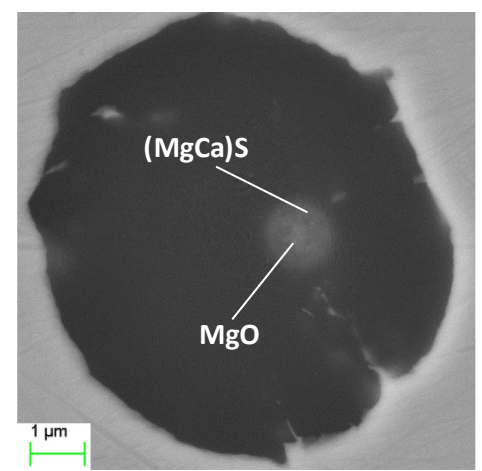

a) Nodule 3.1-15

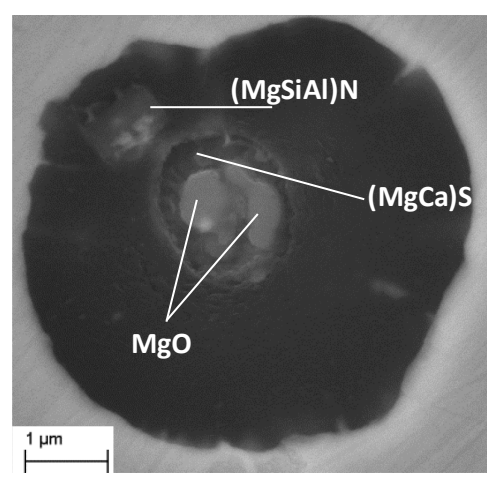

b) Nodule 3.3-5

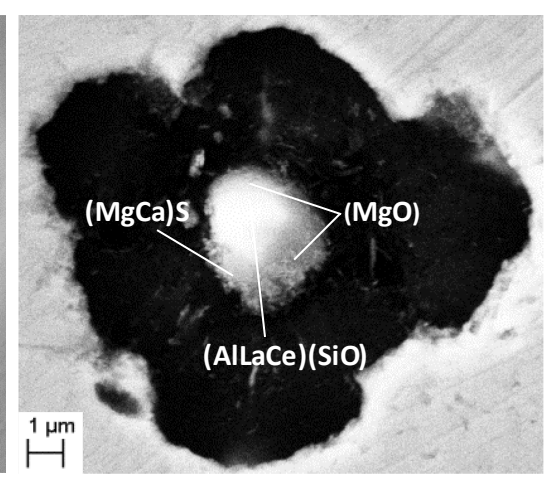

c) Nodule 1.1-3

Figure 4. Examples of nuclei from irons with low percentage of $\mathrm{Ti}$ in the melt

For samples of heat 3, some of these nitrides are enriched in Ti. Oxides and oxysulfides are detected to greater or lesser extent. Some phosphides were also found. No nitrides were detected in the $0.007 \% \mathrm{Ti}$ iron. In this sample, a three-stage nucleation is noted: Mg-Al-RE silicates are at the core of the nuclei; these silicates then nucleate the $\mathrm{Mg}$ oxides which, in turn, act as nuclei for the Mg-Ca sulfides (Figure 4c). 
HIGH PERCENTAGE OF Ti $(0.020-0.036 \%)$

Clearly, for all graphite nodules included in this category, Ti carbonitrides were the majority inclusions, followed by the Mg sulfides or oxy-sulfides. Normally they do not appear alone but combined with one another (Figure 5a). Complex nitrides are important too, but their presence decreases dramatically as the percentage of titanium in the base metal increases. Sometimes, both types of nitrides are part of the same nucleation site (Figure $5 \mathrm{~b})$. No $(\mathrm{MgSiAl}) \mathrm{N}$ were detected as nuclei for samples with the highest percentage of titanium (heat 6). In this range of Ti, some oxides were also found as nuclei. Normally, they were $\mathrm{Mg}$ oxides and they acted as nucleation sites for the sulfides or oxy-sulfides which surrounded them, total or partially. No phosphides and silicates were detected. The majority of the graphite nodules from irons inoculated with $\mathrm{ZrMn}$ (samples 4.2 and 5.2) exhibited zirconium in the nitrides of their inclusions (mainly carbonitrides) (Figure 5c). There was no evidence of the presence of $\mathrm{Mn}$ in the nuclei.

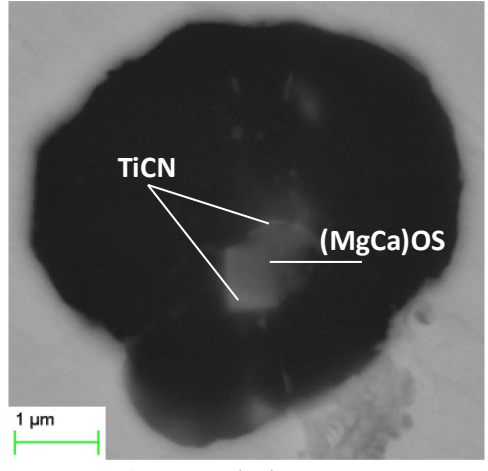

a) Nodule 6.1-3

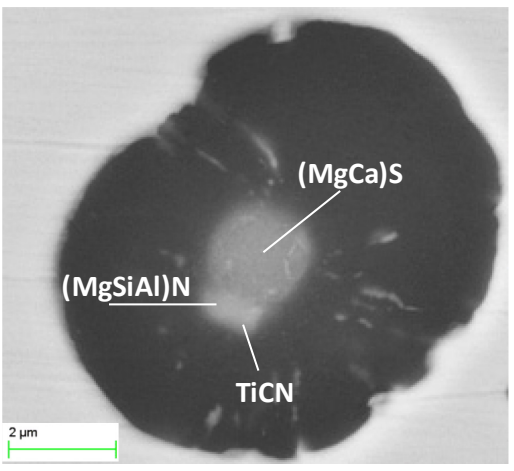

b) Nodule 4.1-10

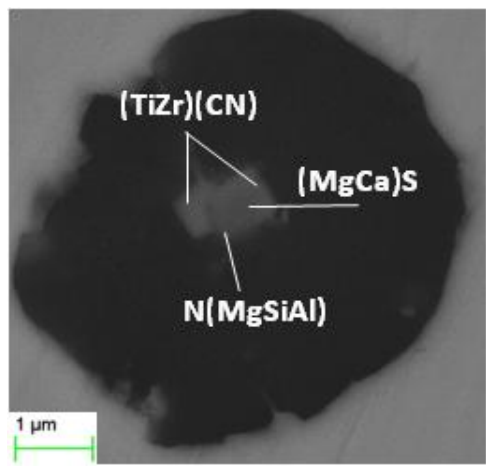

c) Nodule 4.2-11

Figure 5. Examples of nuclei from irons with high percentage of Ti in the melt

\section{Discussion}

The main inclusions in the nuclei in all the samples investigated in this research were $\mathrm{Mg}$ sulfides or oxy-sulfides, which in the most of cases are surrounded totally or partially by (MgSiAl)N or $\mathrm{Ti}(\mathrm{CN})$, depending on the percentage of $\mathrm{Ti}$ in the base metal. In some cases, these sulfides seemed to nucleate on small Mg oxides. The results and analysis in this paper are in line with earlier work by Igarashi and Okada [21].

For irons with very low percentage of Ti, some silicates and some phosphides (Figure 6a), rich in $\mathrm{La}, \mathrm{Ce}$ and $\mathrm{Ba}$, have been found as nuclei. It has been stated in the literature [22] that the phosphorous-containing particles result from reactions occurring during the final stages of solidification, and are located at the grain boundaries without any association with the graphite (Figure 6b). The lack of Ti appears to favor nucleation on phosphides.

There is no significant difference in the type of inclusions generated between inoculated and no inoculated samples. The inoculant affects the nodule count (Ce inoculant seems to be the most effective for low Ti versus ZrMn inoculant for high Ti) but the influence on the nature of the nuclei is not significant in most of the cases. The inoculant rich in aluminum seems to stimulate the formation of $(\mathrm{MgSiAl}) \mathrm{N}$. When the samples are inoculated with an inoculant rich in $\mathrm{RE}$, some inclusions with $\mathrm{Ce}$ and $\mathrm{La}$ are detected (mainly sulfides). However, such sulfides were also found in non-inoculated samples, which suggests that the Ce effect is mostly due to the nodulizing agent. No evidence of bismuth or barium was found. However, the influence of the $\mathrm{ZrMn}$ inoculant is clear, as an increased number of carbonitrides was found, all of them enriched in zirconium (the affinity of Zr to Ti is obvious). 


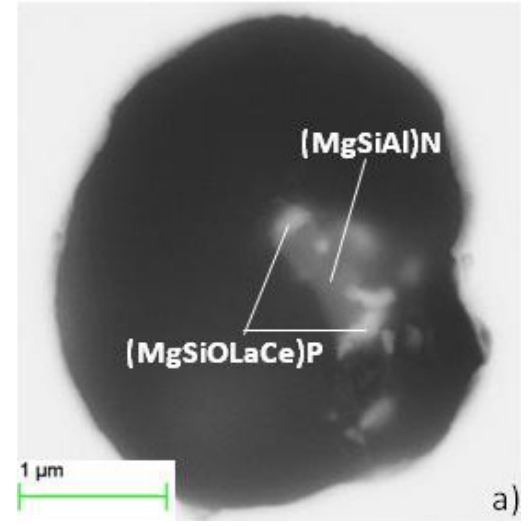

a)

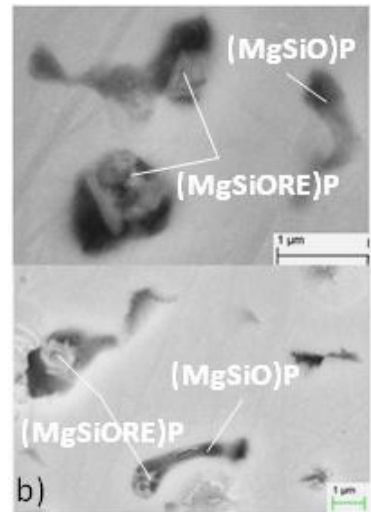

Figure 6. Inclusions of phosphides: a) acting as nuclei for graphite (nodule 2.1-8); b) in the grain boundary without any graphite associated (sample 6.3)

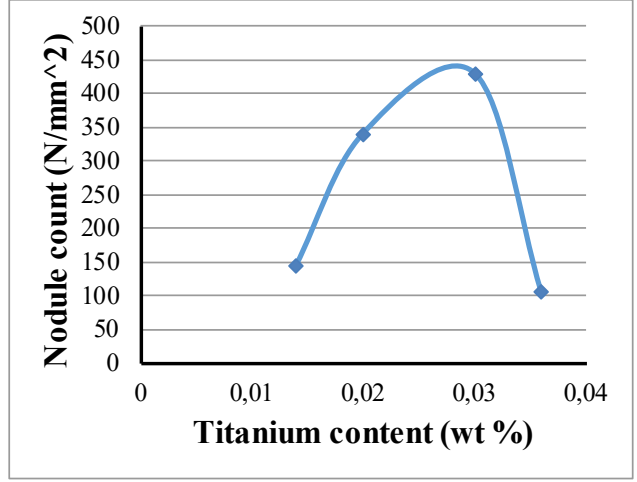

Figure 7. Evolution of the nodule count as a function of the Ti content in the melt for un-inoculated heats

The role of titanium in the nucleation of spheroidal graphite appears to be more important than previously thought. On one hand, the addition of $\mathrm{Ti}$ in the inoculant hardly modifies the nature of the nuclei, but, on the other hand, small changes of its percentage in the base melt alters drastically both the type of inclusions on which the graphite nucleates, and the nodule count (Figure 7). There is a limit (around $0.030 \% \mathrm{Ti}$ ) above which the volumetric density of the graphite nodules decreases (probably the excess of Ti generates coalescence and inclusions in the matrix without graphite).

In irons with low percentage of $\mathrm{Ti}$, no $\mathrm{Ti}(\mathrm{CN})$ were detected and the number of complex (MgSiAl)N was significant. As the percentage of $\mathrm{Ti}$ increases, the number of $\mathrm{Ti}$ carbonitrides is enhanced, and the number of complex nitrides decreases, up to a maximum of $0.036 \% \mathrm{Ti}$ in the iron, where no $(\mathrm{MgSiAl}) \mathrm{N}$ were found as nuclei. This is because the high content of titanium does not allow nitrogen to combine with anything else. Based on these results, it can be concluded that the concentration of titanium in the base metal modifies the preferred nuclei.

The content of titanium in the iron also affects the sequential growth of the nuclei. Only in one case a single compound inclusion was found acting as nucleus (an Al oxide in nodule 5.1-11). For the other instances and independently of the inoculant, the nucleus contained multiple compounds that nucleated on one another in different sequences:

- $(\mathrm{MgCa}) \mathrm{S}$ on $(\mathrm{MgO})$ on $(\mathrm{MgAlLaCe})(\mathrm{SiO})$ for $\mathrm{Ti}<0.010 \%$

- $(\mathrm{MgSiAl}) \mathrm{N}$ on $(\mathrm{MgCa}) \mathrm{S}$ or $(\mathrm{MgCa})(\mathrm{OS})$ on $(\mathrm{MgO})$ for $0.010 \%<\mathrm{Ti}<0.020 \%$

- $\mathrm{Ti}(\mathrm{CN})$ or/and $(\mathrm{MgSiAl}) \mathrm{N}$ on $(\mathrm{MgCa}) \mathrm{S}$ or $(\mathrm{MgCa})(\mathrm{OS})$ for $0.020 \% \leq \mathrm{Ti} \leq 0.030 \%$

- $\mathrm{Ti}(\mathrm{CN})$ on $(\mathrm{MgCa}) \mathrm{S}$ or $(\mathrm{MgCa})(\mathrm{OS})$ for $\mathrm{Ti}>0.030 \%$

\section{Conclusions}

The purpose of this research was to investigate the influence of the trace elements on graphite nucleation in SG iron through quenching experiments and the use of advanced SEM techniques. A series of samples with percentages of $\mathrm{Ti}$ in the base melt ranging from $0.007 \%$ to $0.036 \%$, uninoculated or treated with inoculants containing $\mathrm{Al}, \mathrm{Ce}, \mathrm{Ba}-\mathrm{Bi}-\mathrm{Ce}, \mathrm{Ti}$, or $\mathrm{Zr}-\mathrm{Mn}$ were produced.

$\mathrm{MgCa}$ sulfides or oxysulfides accompanied by $(\mathrm{MgSiAl}) \mathrm{N}, \mathrm{Ti}(\mathrm{CN})$ or both, depending of the content of titanium in the iron, were the main inclusions, regardless of inoculation. Both complex nitrides and carbonitrides seemed to restrict the growth of the sulfides increasing the number of nodules. Some silicates and phosphides were found as nuclei but only in graphite nodules from irons with low content of $\mathrm{Ti}(<0.014 \%)$.

The inoculation apparently did not have a great influence on the nature of nuclei, although there were some exceptions. Ce formed silicates or sulfides, but not in significant numbers. Ba, Bi and Mn were not detected in any graphite. Aluminum favors slightly the formation of complex nitrides and $\mathrm{Zr}$ formed carbonitrides in almost every graphite nodule in iron inoculated with $\mathrm{ZrMn}$. The effect of Ti was very limited when it was used as post inoculant, but paramount when present in the 
iron in amount higher than $0.02 \%$, increasing the nodule count and modifying the nature of the nuclei, i.e. $\mathrm{Ti}(\mathrm{CN})$ instead of $(\mathrm{MgSiAl}) \mathrm{N}$.

The reason for the positive effect of inoculation in all cases is the local supersaturation of Si during the dissolution of the inoculant, which produces higher constitutional undercooling. For the particular case of the $0.02-0.03 \% \mathrm{Ti}$ irons an additional contributing factor is the presence of $\mathrm{Zr}$ in the $\operatorname{Ti}(\mathrm{CN})$ inclusions.

\section{Acknowledgments}

The authors would like to acknowledge Diputacion Foral de Bizkaia for supporting this research.

\section{References}

[1] A. Louvo, E. Alhainen Pellikka and P. Eklund, AFS Trans. 99 (1991) 237-244

[2] I. Asenjo, P. Larrañaga, J. Sertucha, R. Suarez, J.M. Gómez, I. Ferrer and J. Lacaze, Int. J. Cast Met. Res. 20 (2007) 319-324

[3] I. G. Chen and D. M. Stefanescu, AFS Trans. 92 (1984) 947-964

[4] T. Skaland and Ø. Grong, AFS Trans. 99 (1991) 153-157

[5] L. Battezzati, M. Baricco, C.A. Coria, G. Serramoglia and F. Marongiu, Int. J. Cast Met. Res. 16 (2003) 87-92

[6] S. Jung, T. Ishikawa and H. Nakae, Mater. Sci. Eng. A 476 (2008) 350-356

[7] C.R. Loper and K. Fang, AFS Trans. 105 (1997) 147-152

[8] J.V. Dawson, Modern Casting, 49 (1966) 171-177

[9] N.C. McClure, A.V. Khan, D. McCrady and H.L. Womochel, AFS Trans., 65 (1957) 340-349

[10] C.S. Kanetkar, H.H. Carnell and D.M. Stefanescu, AFS Trans. 92 (1984) 417-428

[11] S. Lekakh and C.R. Loper, AFS Trans. 111 (2003) paper 03-103

[12] S.O. Olsen, T. Skaland and C. Hartung, Proc. $66^{\text {th }}$ World Foundry Congress, Istanbul, Turkey, 2004, pp. 891-902

[13]P.J. Bilek, J.M. Dong, T.K. McCluhan, AFS Trans. 80 (1972) 183-188

$[14]$ M. Koch and K. Soulas, "Inoculation of grey and ductile iron", $7^{\text {th }}$ International Ankiros Foundry Congress, Istanbul, Turkey, 2014

[15]L. Quian, Modern Castings, no. 3, (1985) 27-30

[16] J.K. Solberg, M.I Onsøien, Materials Science and Technology, 17 (2001) 1238-1242

[17] G. Alonso, P. Larrañaga, D. M. Stefanescu, E. De la Fuente, A. Natxiondo and R. Suarez, "Kinetics of Nucleation and Growth of Graphite at different Stages of Solidification for Spheroidal Graphite Iron", $72^{\text {nd }}$ World Foundry Congress, 21-25 ${ }^{\text {th }}$ May 2016, Nagoya, Japan

[18]G. Alonso, D.M. Stefanescu, P. Larrañaga, E. De la Fuente and R. Suarez, AFS $121^{\text {st }}$ Metalcasting Congress, 24-27 ${ }^{\text {th }}$ April, Wisconsin, USA, 2017

[19] L.J. Kozlov, A.P. Vorobyev, Cast Metals, 4 (1) (1991)

[20] R.J. Warrick, AFS Cast Metals Research J., Sept., (1966) 97-108

[21] Y. Igarashi and S. Okada, Int. J. Cast Metals Research, 11(2) (1998) 83-88

[22] A. Vahed. and D.A.R. Kay, Metal Trans. B, 7B (1976) 375-383 